\title{
Moderately Decreased Dietary Salt Intake Suppresses the Progression of Renal Insufficiency in Rats with 5/6 Nephrectomy
}

\author{
Jan Burkert, ${ }^{1}$ Anna Steklacova, ${ }^{2}$ Pavel Rossmann, ${ }^{3}$ Jaroslav Spatenka, ${ }^{1}$ \\ Jan Opatrný, ${ }^{4}$ and Karel Matousovic ${ }^{5}$ \\ ${ }^{1}$ Department of Transplantation and Tissue Banking, University Hospital Motol, 15006 Prague, Czech Republic \\ ${ }^{2}$ Charles University 2nd School of Medicine, 15006 Prague, Czech Republic \\ ${ }^{3}$ Institute of Microbiology, Academy of Sciences of the Czech Republic, 14220 Prague, Czech Republic \\ ${ }^{4}$ Department of Cardiology, Charles University School of Medicine, 30460 Plzen, Czech Republic \\ ${ }^{5}$ Department of Medicine, Charles University 2nd School of Medicine and University Hospital Motol, 15006 Prague, Czech Republic
}

Correspondence should be addressed to Karel Matousovic; karel.matousovic@lfmotol.cuni.cz

Received 1 July 2014; Revised 8 September 2014; Accepted 11 October 2014; Published 10 November 2014

Academic Editor: Jane Black

Copyright (C) 2014 Jan Burkert et al. This is an open access article distributed under the Creative Commons Attribution License, which permits unrestricted use, distribution, and reproduction in any medium, provided the original work is properly cited.

\begin{abstract}
Aim. Up to now, an appropriate salt intake in renal insufficiency has not been clearly determined. We hypothesize that even a moderate decrease in salt intake may affect functional and morphologic response of the rat remnant kidney after 5/6 nephrectomy. Methods. Subtotal nephrectomy was performed in 77 inbred 12 week-old-female AVN Wistar rats. The two groups of rats were fed either a standard or a low salt diet. Median of salt intake was 14.6 and $10.4 \mathrm{mg} / 100 \mathrm{~g} / 24 \mathrm{~h}$ in the two groups. Results. Ten weeks after ablation, the remnant kidney parenchyma wet weight was $0.66 \pm 0.16 \mathrm{~g} / 100 \mathrm{~g}$ of body weight and $0.56 \pm 0.11 \mathrm{~g} / 100 \mathrm{~g}$ of body weight $(P<0.01)$ in rats with a standard and low salt diet, respectively. In these two groups, systolic blood pressure was $151 \pm 29$ versus $126 \pm 21 \mathrm{mmHg}(P<0.05)$, serum creatinine levels were $164 \pm 84$ versus $106 \pm 29 \mu \mathrm{mol} / \mathrm{L}(P<0.001)$, proteinuria was $84 \pm 37$ versus $83 \pm 40 \mathrm{mg} / 100 \mathrm{~g} / 24 \mathrm{~h}$ (N.S.), and the glomerular injury score was $2.06 \pm 0.49$ versus $1.43 \pm 0.62(P<0.01)$, respectively. Conclusion. Moderately decreased salt intake slowed down the development of ablation nephropathy in AVN inbred strain of rats.
\end{abstract}

\section{Introduction}

Ablation of 5/6 (83\%) of renal parenchyma in rats is an experimental model of chronic renal failure. Remnant "intact" nephrons respond by increasing single nephron filtration rate and with an impaired regulation of inflammatory mediators production. Later, the systemic hypertension and proteinuria develop. The final fatal consequence is the remnant glomeruli sclerosis, tubular atrophy and interstitial sclerosis (i.e., ablation nephropathy), and renal failure. This process can be reduced by a low protein diet and/or angiotensin converting enzyme inhibitors administration [1] or by the early kidney transplantation [2].

It is well known that low salt intake decreases systemic blood pressure in experimental animals and men [3-7] as well as the incidence of cardiovascular accidents [8]. Low salt intake suppresses asymmetric dimethylarginine (ADMA) formation and therefore nitric oxide $(\mathrm{NO})$ production and downregulates the activity of platelet-derived growth factor (PDGF), interleukin-1 (IL-1), and other proinflammatory cytokines. Consequently, the endothelial function may be modified [8-11] and therefore atherosclerosis and cardiovascular and renal damages reduced [7]. Low salt intake also decreases proximal tubular epithelia hypertrophy [12-14]. In hemodialyzed patients with severe hypertension, low salt intake $(5 \mathrm{~g} / 24 \mathrm{~h})$ caused a decrease in blood pressure due to the decrease in total peripheral resistance [7]. The normotension persisted several months even without antihypertensive therapy. Conversely, high salt intake increases systemic blood pressure, incidence of cardiovascular accidents, and secretion of cardiovascular steroids ("mammalian digitalis") [15-17]. Salt also causes transfer of water from intracellular to extracellular compartment and shifts acid base balance towards metabolic acidosis. 
Previously, it was found that in rats with 5/6 nephrectomy salt-free diet $(0.09 \%$ versus $0.43 \%$ by weight) slowed rate of progression of the ablation nephropathy $[12,18]$. The aim of the present study was to determine if even a mild decrease in salt intake $(0.3 \%$ versus $0.5 \%)$, which corresponds by weight to the recommended salt intake in men (4-5 g/24 h), would affect functional and morphologic response of the rat remnant kidney after 5/6 nephrectomy.

\section{Subjects and Methods}

2.1. Animals. Seventy-seven 16 -week-old inbred AVN female rats (inbred albino rats with low antibody formation response, from the Academy of Sciences of the Czech Republic) weighing $212 \pm 22 \mathrm{~g}$ were used. Rats were randomly assigned to ingest either a standard $(0.5 \%$ by weight; 32 animals) or a salt restricted chow $(0.3 \% ; 45$ rats). The rats were fed ad libitum and food intake was estimated weekly by weighing the animals.

2.2. Operation Technique. Anaesthesia and surgery were performed as in our previous study [2]. Briefly, before the operation, the rats were administered $1 \mathrm{~mL} / 100 \mathrm{~g}$ of body weight of $40 \%$ glucose. Subtotal (5/6) nephrectomy was performed under general anaesthesia (pentobarbital $3.5 \mathrm{mg} / 100 \mathrm{~g}$ of body weight). After a right and left flank incisions, the right kidney and two-thirds of the left kidney (the upper and lower poles) were removed and weighed to estimate the residual weight of kidney tissue (under an assumption that both kidneys had equal weights). The poles were incised by strangulation of thread slings. The fibrin foam stopped bleeding. The animals were killed under ether anaesthesia 10 week later.

2.3. Methods. Before operation and at 4th, 7th, and 10th weeks after 5/6 nephrectomy, the rats were weighed, systemic blood pressure was measured by tail-cuff technique and, approximately one hour later, blood samples from the tail vein were obtained. On the same days, the rats were placed in metabolic cages and $24 \mathrm{~h}$ urine specimens were collected. Serum and the urine concentrations of creatinine, sodium, and protein were measured. The urine output of these compounds was calculated on the basis of their urinary concentrations multiplied by the urine volume. The animals were fed DOS 2 B pellets (contents $20 \%$ protein; Velaz Comp., Czech Republic). Thirty-two animals were fed diet with a conventional $(0.5 \%$ of salt) and 45 with low sodium content $(0.3 \%$ of salt). The sodium intake was estimated in each animal based on the $24 \mathrm{~h}$ urine sodium output at the given intervals, providing its weight before and after its stay in a metabolic cage was comparable. The salt intake was calculated from $24 \mathrm{~h}$ sodium output with relation to the salt molecular mass. Creatinine clearance was calculated by multiplying the serum creatinine concentration by urine volume and this product was divided by the urine creatinine concentration and expressed as $\mathrm{mL} / 100 \mathrm{~g}$ body weight $/ 24 \mathrm{~h}$. Principles of "Laboratory Animal Care" NIH publication Vol. 25, No. 28, revised 1996 were followed and the study was performed with an approval of the Ethical Committee of our Institute.
2.4. Laboratory Tests. Serum and urine creatinine concentrations were assayed by Jaffe reaction, sodium concentration by flame photometry, proteinuria by a pyrogallol red (Bio-Test, Lachema, Brno, Czech Republic).

2.5. Morphometry. For light microscopy, the paraffin sections of formalin-fixed blocks were stained with H.E. and trichrome. As in our previous study [2], the extent of focal and segmental glomerulosclerosis was estimated semiquantitatively in trichrome-stained sections under a rectangular eyepiece graticule net (Carl Zeiss Jena, Germany). Normal glomeruli were scored as zero and those with moderate widening of the mesangium as 1 . The glomeruli with obliterative sclerosis of one capillary loop were scored as 2; those with more sclerosed loops as 4 ; and those with the global sclerosis as 8 . The total number of points in 100 consecutive glomeruli divided by 100 indicates the glomerular index of sclerosis (GIS).

2.6. Statistical Evaluation. For comparison of means, unpaired $t$-test was used. All tests were two-sided, and the $P<0.05$ value was considered as statistically significant.

\section{Results}

To establish a predisposition of AVN rats to ablation nephropathy development, we removed $50 \%$ of renal parenchyma (right-site nephrectomy), 66\% (right-site nephrectomy and resection of the upper pole of the left kidney), and $83 \%$ (right-site nephrectomy and resection of the upper and lower poles of the left kidney) in 20 animals. Ten weeks after ablation, the weight of the residual kidney parenchyma and systolic blood pressure were significantly increased and the creatinine clearance decreased proportionally to the amount of removed renal parenchyma (Table 1). The aim of this pilot study was to find out a predisposition of AVN rats to the loss of renal parenchyma. In 5/6 nephrectomised rats the characteristic morphologic appearance of ablation nephropathy developed (Figure 1). These animals were not included in the following survey.

In our study, the calculated amount of the removed renal parenchyma was $80 \pm 4 \%$ (average $\pm \mathrm{SD}$; median 80 ) in rats with $5 / 6$ nephrectomy. The calculated median of the daily salt intake was $14.6 \mathrm{mg} / 100 \mathrm{~g} / 24 \mathrm{~h}$ and $10.4 \mathrm{mg} / 100 \mathrm{~g} / 24 \mathrm{~h}$ in rats on the conventional and low salt diets, respectively.

At the end of the experiment, the renal parenchyma wet weight per $100 \mathrm{~g}$ of body weight was significantly lower in rats fed low salt diet $(0.66 \pm 0.16$ versus $0.56 \pm 0.11 ; P<0.01$; Figure 2).

Systolic blood pressure was increased in both groups, but it was lower in the group with lower salt intake during the entire follow-up period with statistical significance at the 10th week after ablation $(149 \pm 29$ versus $125 \pm 30 ; P<0.05$; Figure 3).

Serum creatinine levels increased during follow-up less rapidly in the group with lower salt intake with statistical significance at the 10th week $(164 \pm 109$ versus $84 \pm 23 \mu / \mathrm{L}$; $P<0.001$ ) (Figure 4). Creatinine clearance was significantly higher in the group with low salt intake at the end of 
TABLE 1: Relation between the quantity of removed renal parenchyma in AVN rats and increase in remnant parenchyma mass and its functional response at operation and 10 weeks later.

\begin{tabular}{|c|c|c|c|c|c|c|}
\hline & & & oportion of $r$ & ed parenchy & & \\
\hline & & & & & & \\
\hline$n$ & & & & & & \\
\hline & Operation & 10 weeks & Operation & 10 weeks & Operation & 10 weeks \\
\hline Parench. weight $(\mathrm{g} \pm \mathrm{SD})$ & $\mathbf{0 . 7 9} \pm 0.05$ & $1.22 \pm 0.10$ & $\mathbf{0 . 5 2} \pm 0.09$ & $1.10 \pm 0.15$ & $\mathbf{0 . 3 1} \pm 0.09$ & $1.64 \pm 0.35$ \\
\hline S-creatinine $(\mu \mathrm{mol} / \mathrm{L})$ & $46 \pm 10$ & $127 \pm 11$ & $40 \pm 4$ & $137 \pm 18$ & $43 \pm 3$ & $127 \pm 39$ \\
\hline Creat. clear. (mL/24 h/100 g) & $265 \pm 96$ & $249 \pm 30$ & $284 \pm 48$ & $211 \pm 69$ & $263 \pm 78$ & $135 \pm 53$ \\
\hline Proteinuria (mg/24 h/100 g) & $1 \pm 0.5$ & $3 \pm 1.5$ & $1 \pm 0.5$ & $7 \pm 5.5$ & $2 \pm 1$ & $75 \pm 38$ \\
\hline
\end{tabular}

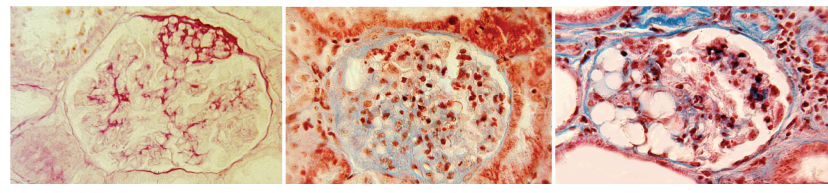

FIGURE 1: Segmental sclerosis and capsular adhesion of one capillary loop (top), grade 2. PAS (left); obliteration of lower part of capillary tuft (grade 4). Blue trichrome (middle); confluent sclerosis of glomerulus with microcystic structures of mesangiolysis (grade 8). Blue trichrome (right).

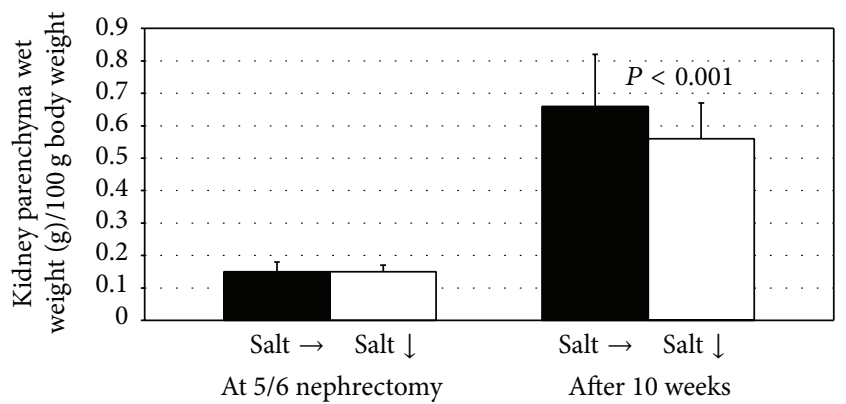

FIGURE 2: The influence of salt intake on the increase of renal parenchyma wet weight in rats after 5/6 nephrectomy. The weight of the remnant parenchyma at 5/6 nephrectomy was calculated from the weights of removed right kidney and the upper and lower poles of the left kidney under an assumption that both kidneys had equal weights.

the experiment $(167 \pm 90$ versus $206 \pm 82 \mathrm{~mL} / 100 \mathrm{~g} / 24 \mathrm{~h}$; $P<0.05)$. After ablation, proteinuria increased in both groups with a high degree of variability and we did not document a significant difference in its levels between the two experimental groups.

The value of GIS (glomerular injury score) at the end of the experiment was $2.06 \pm 0.49$ and $1.43 \pm 0.62(P<0.01)$ in the group with a conventional and low salt intake, respectively (Figure 5).

Body weights of animals in the two groups were comparable before $5 / 6$ nephrectomy ( $218 \pm 37$ and $210 \pm 33$ in groups with normal and lower salt intake, resp.) and it was $251 \pm 43$ and $242 \pm 45 \mathrm{~g}$ at the end of experiment (N.S.).

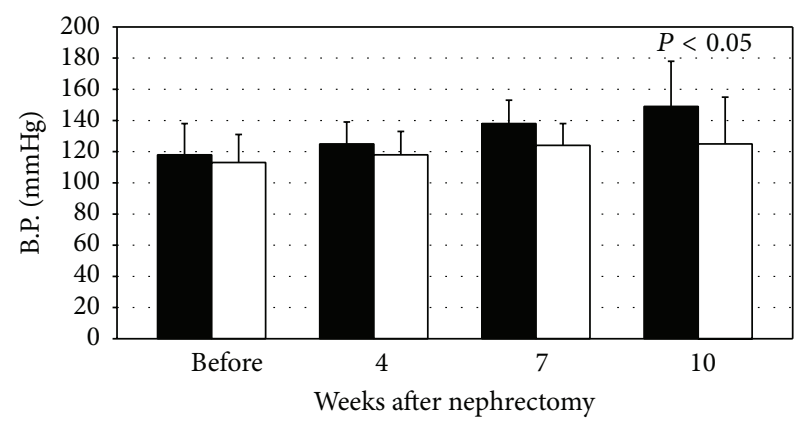

Salt $\rightarrow$

Salt $\downarrow$

FIGURE 3: Influence of salt intake on systolic blood pressure in rats after 5/6 nephrectomy.

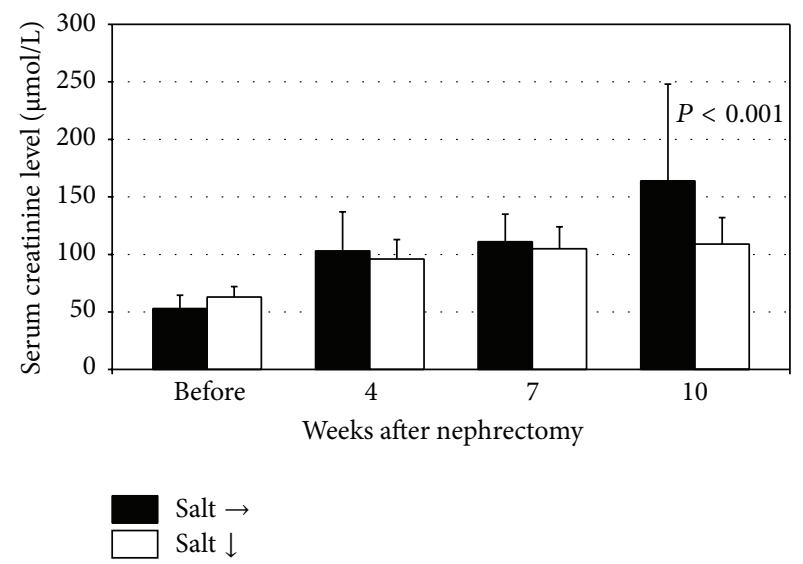

FIGURE 4: Influence of salt intake on serum creatinine levels in rats after 5/6 nephrectomy.

For statistical evaluation, we normalized all findings for $100 \mathrm{~g}$ of body weight.

\section{Discussion}

The current view of the renal disease progression in men was inferred from findings in the 5/6 nephrectomised rats. This procedure results in the syndrome of systemic hypertension, 


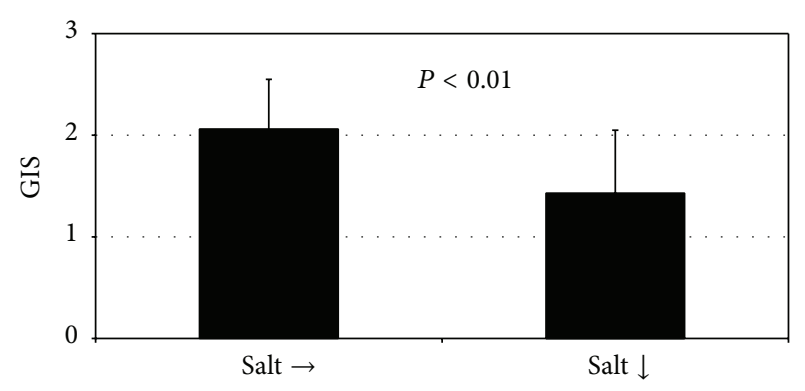

FIGURE 5: Influence of salt intake on the glomerular injury score (GIS) in rats after 5/6 nephrectomy.

proteinuria, and finally renal failure. Morphological evaluation of this lesion revealed glomerular and interstitial sclerosis and tubular atrophy [2]. The micropuncture technique documented more than twofold increase in the single nephron glomerular filtration rate caused by the increases in the afferent blood flow and glomerular capillary hydrostatic pressure and due to an increase in the filtration coefficient of the glomerular capillary wall [3]. These intrarenal hemodynamic changes are accompanied with an impaired regulation of growths factors, cytokines such as profibrogenic TGF $\beta$ [11], reactive oxygen species formation [19], and impaired regulation of other inflammatory mediators [20]. Interestingly, salt restriction in rats with chronic renal failure also minimized the occurrence of the proximal renal tubular hypertrophy [14]. As renal failure progresses, the quantities of dietary salt may substantially influence bicarbonate homeostasis. The reduction of dietary salt resulted in bicarbonate conservation in rats with experimental progressive renal failure [21]. This, until now not fully appreciated acidifying effect of salt, was physiologically explained by the quantitative theory of acid base balance [22].

In men, salt intake correlates with systemic blood pressure and the reduction in salt consumption in patients with essential or renoparenchymatous hypertension or in those on renal replacement therapy decreases blood pressure [11, 2325]. The infrequent reviews evaluating the linkage between dietary salt intake and the progression of renal diseases in men established that increasing dietary salt intake increases urine albumin excretion. The results are insufficient and conflicting as for the effects on renal function, especially over a prolonged time $[8,9,11,13,15,16,26,27]$.

Little is known about the effect of dietary salt intake on the experimental ablation nephropathy course. In MunichWistar rats with 5/6 nephrectomy, fed diet containing either $0.43 \%$ or $0.09 \%$ of salt by weight, the lower increases in the glomerular volume and glomerular capillary radius were observed in the latter group [18]. We found that the protective effect against ablation nephropathy progression might be accomplished also by a moderate reduction in salt intake ( $0.3 \%$ by weight). In our study, the ingested amount of salt was calculated from the urinary sodium output. It varied individually and if converted by the weight ratio for a $70 \mathrm{~kg}$ weighing men, it corresponded to intake of $7.5-10.1 \mathrm{~g}$ of salt $/ 24 \mathrm{~h}$ and $5.2-7.4 \mathrm{~g}$ of salt $/ 24 \mathrm{~h}$ for the conventional and low salt diet groups, respectively. Such a reduction in the salt intake can be easily accomplished in men. In spite of a relatively modest reduction in dietary salt in our study, a more favourable course of ablation nephropathy was noted, both from the laboratory and morphological points of views. To the best of our knowledge, this is the first study that demonstrates the renal protective effect of only moderate decrease in salt intake in $5 / 6$ nephrectomised rats.

The rats were fed ad libitum and therefore there was a possibility that a salt content influenced the food intake. It is apparent from the value of the $24 \mathrm{~h}$ urinary sodium output $(14.6 \mathrm{mg} / 100 \mathrm{~g} / 24 \mathrm{~h}$ and $10.4 \mathrm{mg} / 100 \mathrm{~g} / 24 \mathrm{~h}$ in the group with $0.5 \%$ and $0.3 \%$, resp.) that it corresponds approximately to the same amount of ingested food in both groups. In addition, body weights were not statistically different between the groups at the end of the experiment; therefore, we infer that the food intake was similar in the groups. In patients with the salt sensitive hypertension a change in dietary salt intake from $100 \mathrm{mEq} \mathrm{Na}{ }^{+} / 24 \mathrm{~h}(6 \mathrm{~g}$ of salt) to $236 \mathrm{mEq}$ $\mathrm{Na}^{+} / 24 \mathrm{~h}$ (14 g of salt) for two weeks was associated with a significant increases in protein excretion (from 74 to $138 \mathrm{mg} / 24 \mathrm{~h}$ ) [28]. As for renal function, renal patients with creatinine clearance between 10 and $40 \mathrm{~mL} / \mathrm{min}$., kept on a low salt diet $(<100 \mathrm{mEq} / 24 \mathrm{~h})$, showed an improvement in renal outcome over the 3-year period of observation when compared with a similar group on a higher dietary salt $\left(>200 \mathrm{mEq}\right.$ of $\mathrm{Na}^{+} / 24 \mathrm{~h}$ ).

We assessed the level of the renal parenchyma hypertrophy according to its wet weight at the end of the experiment. It was consistently lower in rats with salt restriction $(P<0.01)$. While in the salt-restricted rats the weight of the remnant kidney parenchyma achieved $68 \%$ of the calculated weight of both autologous kidney, it was as much as $77 \%$ in the group with a conventional salt intake at the end of the experiment.

Significant difference in GIS between the two groups of rats in favour of those with low sodium intake can be partially ascribed to lower systemic blood pressure. However, direct and blood pressure independent effects of high salt intake were identified, like the upregulation of TGF $\beta$ in the kidneys and aortic endothelia, changes of cell secondary signalling pathways and NO formation [29].

Serum creatinine level was lower and creatinine clearance higher in the group fed diet with lower sodium content. We speculate that these findings mirror the larger preserved filtration area of the glomerular capillaries in rats with less advanced glomerular sclerosis and perhaps a higher number of preserved nephrons at the end of the experiment.

The normotensive inbred AVN strain of rats is susceptible to the development of ablation nephropathy, as proved by a proportionality of functional and morphologic impairments to the amount of removed renal parenchyma and the development of the ablation nephropathy ten weeks after 5/6 nephrectomy, as proved by our previous experiments [2]. The rapidity of development of these pathological changes is genetically determined [30].

Thus, a mild dietary salt reduction, in addition to salt free diet and ACEI administration, may provide an additional means which partially prevents the progression of the remnant kidney damage in rats with 5/6 nephrectomy. 


\section{Conflict of Interests}

The authors declare that there is no conflict of interests regarding the publication of this paper.

\section{Acknowledgments}

This investigation was supported by the Grant IGA NT11081 from the Grant Agency of the Ministry of Health, Czech Republic, and by the Grant 00064203 of the Ministry of Health, RVO, Czech Republic.

\section{References}

[1] Z. Krivosíkova, K. Sebekova, V. Spustova, I. Lajdova, and R. Dzurik, "Enalapril in subantihypertensive dosage attenuates kidney proliferation and functional recovery in normotensive ablation nephropathy of the rat," Physiological Research, vol. 48, no. 6, pp. 429-435, 1999.

[2] P. Rossmann, I. Ríha, K. Matousovic, M. Bohdanecka, and A. Buckovsky, "Experimental ablation nephropathy: fine structure, morphometry, cell membrane epitopes, glomerular polyanion and effect of subsequent transplantation," Pathology-Research and Practice, vol. 186, no. 4, pp. 491-506, 1990.

[3] T. H. Hostetter, T. W. Meyer, H. G. Rennke, and B. M. Brenner, "Chronic effects of dietary protein in the rat with intact and reduced renal mass," Kidney International, vol. 30, no. 4, pp. 509-517, 1986.

[4] J. M. Geleijnse, F. J. Kok, and D. E. Grobbee, "Blood pressure response to changes in sodium and potassium intake: a metaregression analysis of randomised trials," Journal of Human Hypertension, vol. 17, no. 7, pp. 471-480, 2003.

[5] P. Ylitalo, R. Hepp, and P. Oster, "Effects of varying sodium intake on blood pressure and renin angiotensin system in subtotally nephrectomized rats," Journal of Laboratory and Clinical Medicine, vol. 88, no. 5, pp. 807-816, 1976.

[6] G. A. MacGregor, N. D. Markandu, G. A. Sagnella, D. R. J. Singer, and F. P. Cappuccio, "Double-blind study of three sodium intakes and long-term effects of sodium restriction in essential hypertension," The Lancet, vol. 2, no. 8674, pp. 12441247, 1989.

[7] S. Shaldon and J. Vienken, "The long forgotten salt factor and the benefits of using a 5-g-salt-restricted diet in all ESRD patients," Nephrology Dialysis Transplantation, vol. 23, no. 7, pp. 2118-2120, 2008.

[8] B. D. Dickinson and S. Havas, "Reducing the population burden of cardiovascular disease by reducing sodium intake: a report of the council on science and public health," Archives of Internal Medicine, vol. 167, no. 14, pp. 1460-1468, 2007.

[9] C. Jones-Burton, S. I. Mishra, J. C. Fink et al., "An indepth review of the evidence linking dietary salt intake and progression of chronic kidney disease," The American Journal of Nephrology, vol. 26, no. 3, pp. 268-275, 2006.

[10] C. Zoccali and F. Mallamaci, "The salt epidemic: old and new concerns," Nutrition, Metabolism and Cardiovascular Diseases, vol. 10, no. 3, pp. 168-171, 2000.

[11] P. W. Sanders, "Salt intake, endothelial cell signaling, and progression of kidney disease," Hypertension, vol. 43, no. 2, pp. 142-146, 2004.

[12] L. D. Dworkin, J. A. Benstein, E. Tolbert, and H. D. Feiner, "Salt restriction inhibits renal growth and stabilizes injury in rats with established renal disease," Journal of the American Society of Nephrology, vol. 7, no. 3, pp. 437-442, 1996.

[13] S. Kuriyama, H. Tomonari, Y. Ohtsuka, H. Yamagishi, I. Ohkido, and T. Hosoya, "Salt intake and the progression of chronic renal diseases," Nippon Jinzo Gakkai Shi, vol. 45, no. 8, pp. 751-758, 2003.

[14] K. Okada and K. Matsumoto, "Effect of dietary salt restriction on tubular hypertrophy in rats with early-stage chronic renal failure," Scandinavian Journal of Urology and Nephrology, vol. 38, no. 4, pp. 326-331, 2004.

[15] E. Ritz, N. Koleganova, and G. Piecha, "Role of sodium intake in the progression of chronic kidney disease," Journal of Renal Nutrition, vol. 19, no. 1, pp. 61-62, 2009.

[16] E. Ritz and O. Mehls, "Salt restriction in kidney disease-a missed therapeutic opportunity?" Pediatric Nephrology, vol. 24, no. 1, pp. 9-17, 2009.

[17] J. Titze and E. Ritz, "Salt and its effect on blood pressure and target organ damage: new pieces in an old puzzle," Journal of Nephrology, vol. 22, no. 2, pp. 177-189, 2009.

[18] D. S. Lax, J. A. Benstein, E. Tolbert, and L. D. Dworkin, "Effects of salt restriction on renal growth and glomerular injury in rats with remnant kidneys," Kidney International, vol. 41, no. 6, pp. $1527-1534,1992$.

[19] C. Kitiyakara, T. Chabrashvili, Y. Chen et al., "Salt intake, oxidative stress, and renal expression of NADPH oxidase and superoxide dismutase," Journal of the American Society of Nephrology, vol. 14, no. 11, pp. 2775-2782, 2003.

[20] C. Chatziantoniou and J.-C. Dussaule, "Is kidney injury a reversible process?" Current Opinion in Nephrology and Hypertension, vol. 17, no. 1, pp. 76-81, 2008.

[21] C. H. Espinel, "The influence of salt intake on the metabolic acidosis of chronic renal failure," Journal of Clinical Investigation, vol. 56, no. 2, pp. 286-291, 1975.

[22] P. A. Stewart, "Modern quantitative acid-base chemistry," Canadian Journal of Physiology and Pharmacology, vol. 61, no. 12, pp. 1444-1461, 1983.

[23] E. Matyas, K. Jeitler, K. Horvath et al., "Benefit assessment of salt reduction in patients with hypertension: systematic overview," Journal of Hypertension, vol. 29, no. 5, pp. 821-828, 2011.

[24] E. Ritz, "Salt and hypertension," Nephrology, vol. 15, supplement 2, pp. 49-52, 2010.

[25] M. H. Alderman, "Dietary sodium and cardiovascular health in hypertensive patients: the case against universal sodium restriction," Journal of the American Society of Nephrology, vol. 15, supplement 1, pp. S47-S50, 2004.

[26] T. F. Antonios and G. A. MacGregor, "Salt-more adverse effects," The Lancet, vol. 348, no. 9022, pp. 250-251, 1996.

[27] J. A. Krikken, G. U. Laverman, and G. Navis, "Benefits of dietary sodium restriction in the management of chronic kidney disease," Current Opinion in Nephrology and Hypertension, vol. 18, no. 6, pp. 531-538, 2009.

[28] M. R. Weir, D. R. Dengel, M. T. Behrens, and A. P. Goldberg, "Salt-induced increases in systolic blood pressure affect renal hemodynamics and proteinuria," Hypertension, vol. 25, no. 6, pp. 1339-1344, 1995.

[29] E. Ritz, R. Dikow, C. Morath, and V. Schwenger, "Salt-a potential "uremic toxin"?" Blood Purification, vol. 24, no. 1, pp. 63-66, 2006.

[30] G. Kökény, Z. Németh, M. Godó, and P. Hamar, "The Rowett rat strain is resistant to renal fibrosis," Nephrology Dialysis Transplantation, vol. 25, no. 5, pp. 1458-1462, 2010. 


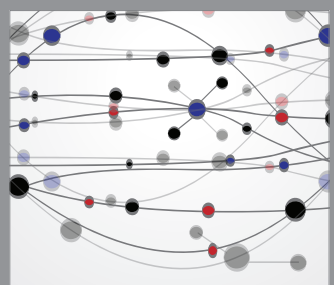

The Scientific World Journal
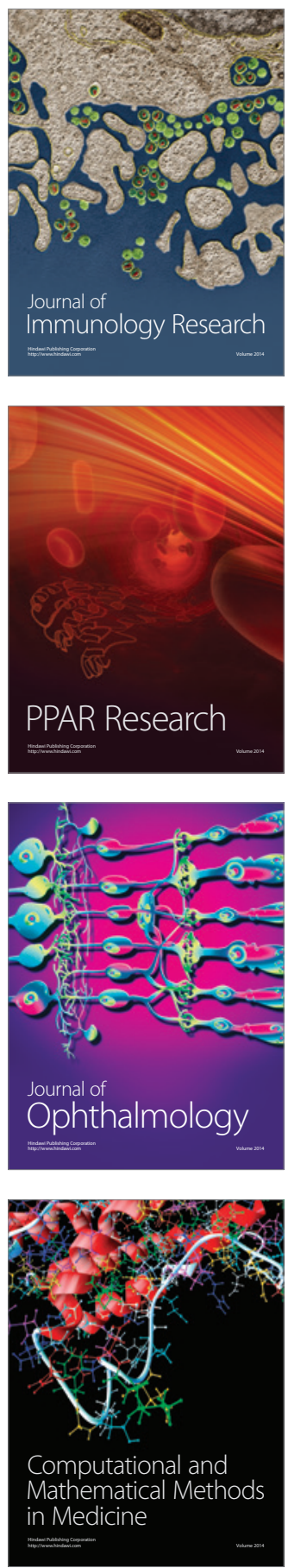

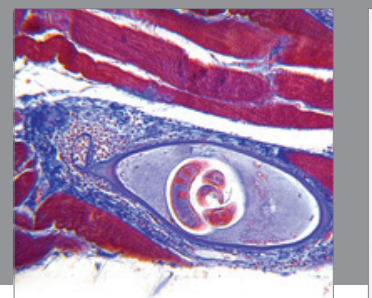

Gastroenterology

Research and Practice
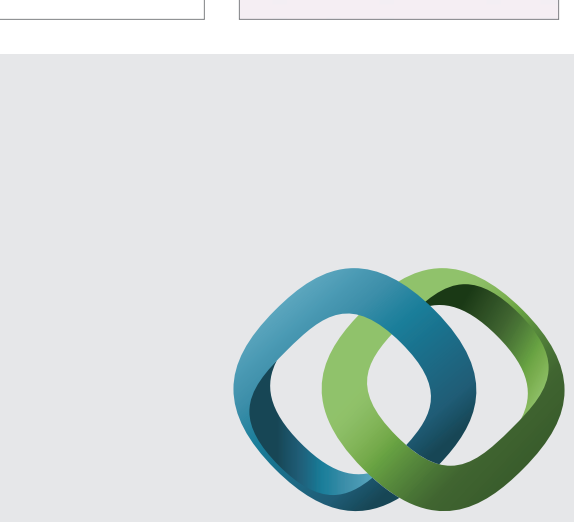

\section{Hindawi}

Submit your manuscripts at

http://www.hindawi.com
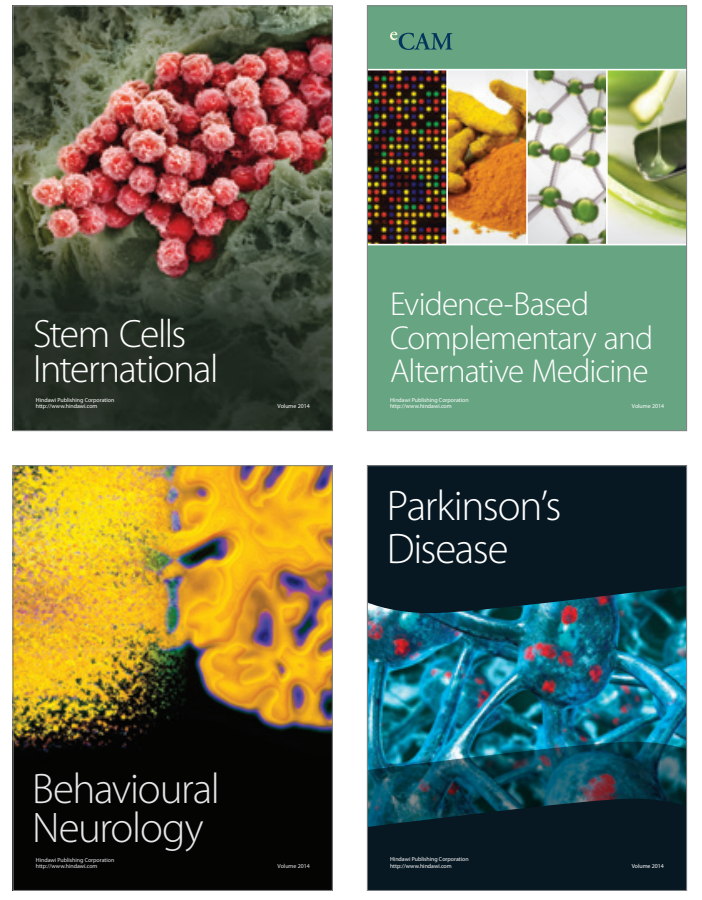
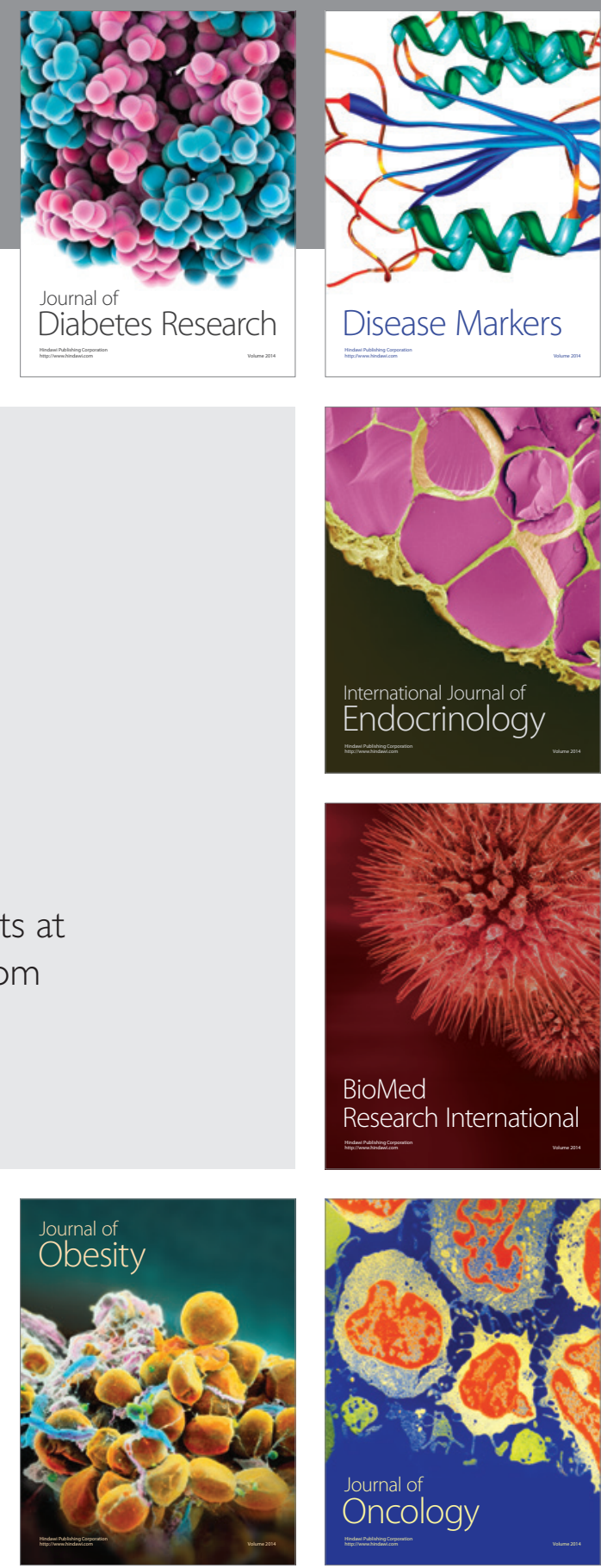

Disease Markers
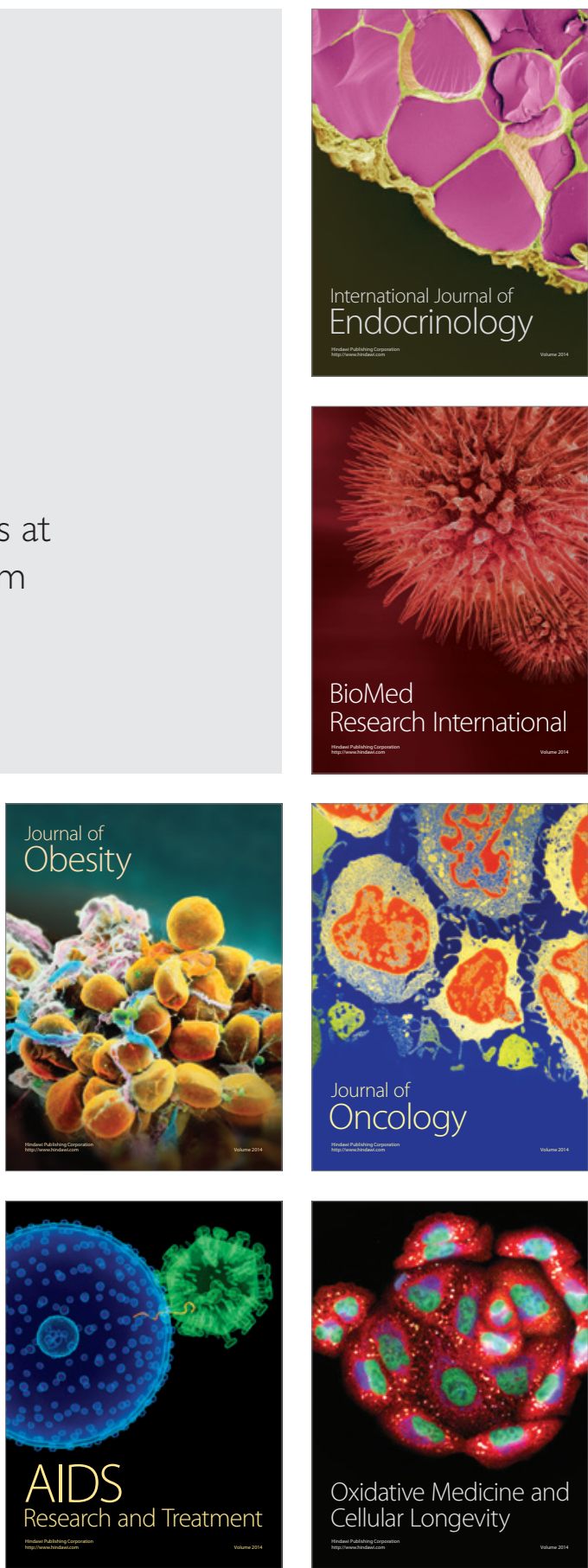